\title{
The optional approach of oncogene-addicted non-small cell lung cancer with brain metastases in the new generation targeted therapies era
}

\author{
Alessia Spagnuolo ${ }^{1}$, Matteo Muto ${ }^{2}$, Fabio Monaco ${ }^{3}$, Giuseppe Colantuoni ${ }^{1}$, Cesare Gridelli ${ }^{1}$ \\ ${ }^{1}$ Division of Medical Oncology, ${ }^{2}$ Division of Radiotherapy, ${ }^{3}$ Division of Radiation Protection, 'S. G. Moscati' Hospital, Avellino, Italy \\ Contributions: (I) Conception and design: All authors; (II) Administrative support: All authors; (III) Provision of study materials or patients: All \\ authors; (IV) Collection and assembly of data: All authors; (V) Data analysis and interpretation: All authors; (VI) Manuscript writing: All authors; \\ (VII) Final approval of manuscript: All authors. \\ Correspondence to: Cesare Gridelli. Division of Medical Oncology, 'S. G. Moscati’ Hospital, Avellino, Italy. Email: cgridelli@libero.it.
}

\begin{abstract}
In recent years, the study of the molecular characteristics of non-small cell lung cancer (NSCLC) has highlighted a specific role of some genes that represent important therapeutic targets, including epidermal growth factor receptor (EGFR), anaplastic lymphoma kinase (ALK), c-ros oncogene 1 (ROS1) and v-Raf murine sarcoma viral oncogene homolog B1 (BRAF). Patients with oncogene-addicted cancer benefit more from therapy with tyrosine kinase inhibitors (TKIs) than from chemotherapy. The brain is a preferred site for tumor spread in these patients. In addition, given greater control of extracranial disease and prolonged survival, the brain is often the first site of progression. Therefore, there is great interest in therapeutic approaches that optimize the control of intracranial disease associated with systemic drugs that, by penetrating the blood-brain barrier (BBB), may improve local control. On the latter, radiotherapy provides excellent efficacy but following the results of clinical trials with new brain penetrant drugs, the question of how and especially when to perform brain radiotherapy in patients with oncogene-addicted NSCLC remains open. Prospective studies may indicate which patients are most likely to benefit from combined use or in what sequence they will undergo systemic and radiotherapy treatment. Due to the heterogeneity of patients and the introduction of new generation TKIs, a multidisciplinary assessment for the best management of therapies in NSCLC patients with molecular driver alterations and brain metastases $(\mathrm{BM})$ is required.
\end{abstract}

Keywords: Brain metastases (BM); driver mutations; non-small cell lung cancer (NSCLC); radiotherapy; tyrosine kinase inhibitors (TKIs)

Submitted Oct 23, 2019. Accepted for publication Nov 13, 2019.

doi: 10.21037/tlcr.2019.12.24

View this article at: http://dx.doi.org/10.21037/tlcr.2019.12.24

\section{Introduction}

The treatment of advanced non-small cell lung cancer (NSCLC) uses different therapeutic strategies chosen based on the biological characteristics of disease and the patient's clinical conditions in order to balance the benefits and side effects associated with prolonged therapy and maintain a satisfactory quality of life. Numerous molecular alterations of NSCLC are now known that affect the tumor biology and represent a valid therapeutic target for molecular target treatments (oncogene-addicted disease). In particular, in adenocarcinoma have been identified activating mutations of epidermal growth factor receptor (EGFR) (in 10-15\% of Caucasian patients and up to $40 \%$ of Asian patients), rearrangements of anaplastic lymphoma kinase (ALK) (in about $3-7 \%$ of cases), c-ros oncogene 1 (ROS-1) (in about $1-2 \%$ of the cases) and mutations of $\mathrm{v}$-Raf murine sarcoma viral oncogene homolog B1 (BRAF) among the most relevant molecular driver aberrations (1-4). Patients 
with specific types of oncogene-addicted tumor have a particularly high incidence of metastasis to the brain, typical site for dissemination of lung cancer, which at diagnosis exceeds $20 \%$ and reaches about $30-40 \%$ of EGFR-mutated and ALK-rearranged cases, respectively. The proportion rises during the course of the disease $(5,6)$. Recognizing the heterogeneity of NSCLC, the peculiarities of clinical contexts, and the availability of various treatment options for brain metastases (BMs) (surgery, radiotherapy and systemic therapy), research now places increasing attention on personalizing care, which allows better treatment management in NSCLC patients with oncogenic drivers and BMs.

\section{Systemic therapy for BMs from oncogene- addicted NSCLC}

\section{With EGFR mutation}

At least eight randomized phase III studies have shown, in patients with advanced EGFR-mutated NSCLC, the superiority of an oral treatment with an EGFR tyrosine kinase inhibitor (TKI) such as gefitinib (250 mg daily), erlotinib (150 mg daily) or afatinib (40 $\mathrm{mg}$ per day) in firstline therapy compared to standard platinum-based chemotherapy, in terms of response rate (RR) and progression-free survival (PFS) (7-14). These are small molecules that are effective in blocking EGFR-mediated signal transduction through binding to the ATP attack site in the EGFR mutated kinase domain. Due to the blockage of the downstream transduction signal, cell proliferation is arrested and cell death is induced via the intrinsic apoptotic pathway (15). The median PFS in the cited studies were between 8.4 and 13.1 months for EGFR inhibitors, and between 4.6 and 6.9 months for chemotherapy. However, none of these individual studies showed a significant advantage in overall survival (OS), probably because many patients treated with chemotherapy received an EGFR inhibitor in subsequent treatment lines, and because the studies were not designed to observe differences in OS. A joint analysis of two randomized phase III studies of similar design, the LUX-Lung 3 and LUX-Lung 6 studies (in which patients were randomized to receive afatinib versus chemotherapy) showed, in the subgroup of patients with classical EGFR mutation, a small but significant advantage in OS in favor of afatinib compared to chemotherapy [median OS, 27.3 versus 24.3 months, hazard ratio (HR) $0.81,95 \%$ confidence interval (CI): 0.66-0.99,
$\mathrm{P}=0.037]$ (16). Although there are few data available on the efficacy of EGFR TKIs in the case of uncommon mutations, it is believed that the rare mutations of exons 18-21 confer sensitivity to treatment, with the exception of insertions of exon 20 and de novo T790M mutation in exon 20 which instead constitute mutations of resistance for inhibitors of the first-(gefitinib and erlotinib) and second- (afatinib) generation (17-23). In the population of EGFR-mutated patients with BMs, gefitinib and erlotinib led to an intracranial objective response rate (ICR ORR) of over $50 \%$ (24-27). Actually, depending on the criteria used in the selection of patients, the range of responses varied between $10 \%$ and $88 \%$, also considering that both compounds show a limited ability to cross the blood-brain barrier (BBB) and therefore to penetrate in the central nervous system (CNS), being recognized by efflux pumps $\mathrm{ABCB} 1$ and $\mathrm{ABCG} 2$ present at that site (27-31). In a prospective phase II study of 28 patients with EGFR-mutated NSCLC and BMs treated with gefitinib or erlotinib, a disease control rate (DCR) of $93 \%$ was achieved, with median PFS and OS of 6.6 months (95\% CI: 3.8-9.3 months) and 15.9 months (95\% CI: 7.2-24.6 months), respectively. There were no differences in PFS and OS based on the EGFR TKI used (26). And 15.2 months of PFS (95\% CI: 8.322.2 months) were achieved with erlotinib with an objective response in 6 of the 8 patients with known EGFR mutation enrolled in a phase II study of 48 pretreated NSCLC patients with BMs. OS for patients with EGFR mutation was 37.5 months (32). A prospective study with gefitinib in 41 NSCLC patients with BMs, pretreated or not, not selected for EGFR, showed a $27 \%$ DCR (95\% CI: $13-40 \%$ ) and a median partial response (PR) duration of 13.5 months (33). Retrospective analyses evaluated the role of the two TKIs for NSCLC BMs: in the first study, of 69 identified patients treated with erlotinib, 17 presented EGFR mutation and achieved an ORR of $82.4 \%$, a time to IC progression (TTIP) median of 11.7 months (95\% CI: 7.9-15.5 months) and an OS of 12.9 months (95\% CI: 6.219.7 months) (28). In the second study, the median OS of patients receiving erlotinib $(n=11)$ was not significantly longer than that of patients receiving gefitinib $(n=52)(25.0$ versus 18.1 months, HR $0.81, \mathrm{P}=0.45$ ) but almost no brain progression occurred in the erlotinib group compared with a median TTIP of 10.8 months in the gefitinib group $(\mathrm{P}=0.02)$ (34). From a previous retrospective study, erlotinib had been shown to prolong the survival of NSCLC patients with leptomeningeal carcinomatosis compared to gefitinib, although without statistical significance (35). Another study 
in patients with BMs and EGFR mutation reported that, unlike gefitinib, erlotinib therapy was a favorable prognostic factor (36). Still, a progressive CNS disease proportion rate between $2.9 \%$ and $4.8 \%$ was reported from prospective and retrospective studies after treatment with erlotinib (37-39). The proportion of cases with CNS progression after erlotinib therapy was smaller than that with gefitinib, as shown in the randomized phase II study NEJ005 (40). The rate of brain progression was less than $10 \%$ in studies with erlotinib and $25 \cdot 1-39.4 \%$ in studies with gefitinib $(40,41)$. However, from a pooled analysis of published data, therapy with EGFR TKIs for NSCLC patients with BMs was particularly effective in patients with EGFR mutation, in which ORR and DCR rates of $85 \%$ and $94.6 \%$ respectively were observed, with a PFS of 12.3 months and an OS of 16.2 months (42). Erlotinib and gefitinib dose variations have been studied to increase the concentration of the drug in cerebrospinal fluid (CSF) (43-45), but without leading to lasting responses (46) and with lower tolerability of high doses of TKIs by patients. Afatinib is a second-generation irreversible EGFR TKI, characterized by a limited ability to exceed $\mathrm{BBB}$, even lower than that of first-generation TKIs, but pretreated patients with EGFR TKI-resistant NSCLC and BMs benefit from its use, with brain disease control in $66 \%$ of cases (47). In patients without brain involvement at diagnosis, the rate of brain progression with afatinib was $7.2 \%$ and $5.4 \%$ in the LUX-Lung 3 and LUXLung 6 trials, respectively (48). Furthermore, PFS and ORR were examined in patients with asymptomatic BMs in both studies $(13,14,48)$. Eighty-one patients had BMs and common EGFR mutations (35 patients in LUX-Lung 3 and 46 in LUX-Lung 6), 10 the patients with BMs and uncommon EGFR mutations. The median PFS was longer with afatinib compared to chemotherapy in the 81 patients (11.1 versus 5.4 months, HR 0.54, $\mathrm{P}=0.1378$ in LUX-Lung 3 and 8.2 versus 4.7 months, HR $0.47, P=0.1060$ in LUXLung 6) but the differences did not reach statistical significance. From a combined analysis of the data, afatinib significantly improved the median PFS in these patients (8.2 versus 5.4 months, $\mathrm{HR} 0.50,95 \% \mathrm{CI}: 0.27-0.95, \mathrm{P}=0.0297$ ). No significant difference in OS was observed in patients with BMs with afatinib versus chemotherapy. ORR was greater with afatinib than with chemotherapy in patients with BMs and common EGFR mutations. In the randomized phase II trial LUX-Lung 7 comparing afatinib to gefitinib as first-line treatment in 319 patients with advanced NSCLC and classical mutation of EGFR, the differences in PFS in patients with $(7.2$ versus 7.4 months for afatinib and gefitinib, respectively, HR 0.76, 95\% CI: $0.41-1.44$ ) or without (12.7 versus 10.9 months, respectively, HR 0.74, 95\% CI: 0.56-0.98) BMs were similar to the difference in PFS observed with afatinib versus gefitinib in the global population (11.0 versus 10.9 months, HR 0.73, 95\% CI: 0.57-0.95, P=0.017) (49). Evidence of emergence in about $60 \%$ of EGFR-mutated patients of T790M resistance mutation in EGFR exon 20 that reduces the activity of first- and second-generation TKIs has led to the development of third-generation EGFR TKIs (50-54). Of these, the clinical evolution of rociletinib and olmutinib was discontinued after an unsatisfactory pattern of efficacy and/or safety (55). On the other hand, osimertinib is an irreversible oral inhibitor of EGFR that exhibits sensitizing mutations and T790M mutation, successfully developed for NSCLC with these molecular characteristics. It crosses the $\mathrm{BBB}$ and inhibits the growth of CNS metastasis in mouse models (56). Goss et al. reported an ORR IC of 54\% with osimertinib in $50 \mathrm{~T} 790 \mathrm{M}$-positive patients after previous EGFR TKIs (57). In the randomized phase III study AURA 3 on 419 pretreated patients with T790M-positive advanced NSCLC, PFS was significantly better with osimertinib (80 $\mathrm{mg}$ daily) than with chemotherapy (10.1 versus 4.4 months, HR 0.30, 95\% CI: $0.23-0.41, \mathrm{P}<0.001)$ with an advantage also observed in the 144 patients with BMs (8.5 versus 4.2 months, HR 0.32, 95\% CI: 0.21-0.49) (58). Compared with the other TKIs, osimertinib showed a better CNS efficacy in 61 patients with asymptomatic BMs (59). The median CNS PFS was higher with osimertinib compared to standard EGFR TKIs (HR 0.48, 95\% CI: $0.26-0.86, \mathrm{P}=0.014)$, with CNS ORRs of $66 \%$ and $43 \%$ respectively (odds ratio, $2.5,95 \%$ CI: $1.2-5.2$, $\mathrm{P}=0.011$ ). In the phase I study BLOOM, AZD3759, EGFR inhibitor primarily thought to cross the $\mathrm{BBB}$, showed promising clinical activity in NSCLC patients with BMs and EGFR mutation but has poor activity in the T790Mpositive NSCLC $(60,61)$. The study also demonstrated the activity of osimertinib in leptomeningeal carcinomatosis from EGFR-mutated NSCLC in 10 (radiological improvement) and 13 patients (stable disease) out of 23 evaluated with brain imaging (62). Selected trials with EGFR TKIs for NSCLC with BMs are shown in Table 1.

\section{With ALK rearrangement}

Patients with ALK-positive disease frequently show BMs, with percentages of $35 \%$ up to $50 \%$ of patients enrolled with BMs $(65,66)$. The incidence rises during the course 
Table 1 CNS ORRs and DCRs from selected trials with EGFR TKIs for advanced NSCLC

\begin{tabular}{lcccl}
\hline Reference & CNS ORR (\%) & CNS DCR $(\%)$ & Compound & Indication \\
\hline$(26)$ & 83 & 93 & Erlotinib or gefitinib & Pretreated or not EGFRm NSCLC \\
$(32)$ & 58.3 & - & Erlotinib & Pretreated NSCLC \\
$(33)$ & PRs [10]; SD [17] & 27 & Gefitinib & Pretreated or not NSCLC \\
$(47)$ & 16 & 66 & Afatinib & Pretreated NSCLC \\
$(48)$ & $70-75$ & $89.3-95$ & Afatinib & Not pretreated EGFRm NSCLC \\
$(57)$ & 54 & 92 & Osimertinib & Pretreated T790M+ NSCLC \\
$(59)$ & 66 & - & Osimertinib & Not pretreated EGFRm NSCLC \\
$(62)$ & 81 & Osimertinib & Pretreated EGFRm NSCLC \\
$(60)$ & PRs [31]; SD [40] & 89 & AZD3759 & EGFRm NSCLC (not pretreated with EGFR TKIs) \\
$(63)$ & 55 & 72 & Icotinib & Pretreated or not EGFRm NSCLC \\
$(64)$ & 50 & - & Lazertinib & Pretreated EGFRm NSCLC \\
\hline
\end{tabular}

CNS ORR, central nervous system objective response rate; DCR, disease control rate; EGFR TKIs, epidermal growth factor receptor tyrosine kinase inhibitors; NSCLC, non-small cell lung cancer; PR, partial response; SD, stable disease.

of the disease: even $60 \%$ of patients may develop BMs primarily after treatment with crizotinib (67), first approved oral ALK inhibitor that significantly improved survival and tumor response in ALK-positive NSCLC patients when compared with standard chemotherapy $(65,67,68)$. In the randomized first-line phase III study PROFILE 1014 for ALK-rearranged NSCLC, of the 343 patients in the intention-to-treat (ITT) population, $23 \%$ had stable BMs at baseline. In these patients, IC DCR was significantly higher with crizotinib (250 $\mathrm{mg}$ twice daily) versus chemotherapy at 12 weeks $(85 \%$ versus $45 \%, \mathrm{P}<0.001)$ and 24 weeks $(56 \%$ versus $25 \%$ respectively, $\mathrm{P}=0.006)$. PFS was significantly longer with crizotinib versus chemotherapy in both the subgroup with $\mathrm{BMs}$ (HR 0.40, $\mathrm{P}<0.001$; median, 9.0 versus 4.0 months respectively) and those without (HR 0.51, $\mathrm{P}<0.001$; median, 11.1 versus 7.2 months respectively) and in the ITT population (HR $0.45, \mathrm{P}<0.001$; median, 10.9 versus 7.0 months respectively). The isolated CNS progression was more frequent in the crizotinib arm (69). In the joint analysis of the phase II studies PROFILE 1005 and phase III 1007, IC DCR was 56\% (95\% CI: 46-66\%) in 109 patients with untreated asymptomatic BMs and $62 \%$ (95\% CI: 54-70\%) in 166 patients with previously treated BMs. In the former, the median TTIP was 7 months while in the last 13.2 months. Among patients without baseline BMs, 20\% developed BMs after initiation of crizotinib, supporting the hypothesis of inadequate drug concentration in the CNS (70) due to the poor ability to penetrate through the BBB $(71,72)$. Strategies that include higher doses of crizotinib combined with chemotherapy and BBB efflux pump inhibition have been investigated to increase efficacy in the CNS $(73,74)$. ALK newer generation inhibitors that exceed crizotinib resistance with improved CNS activities are currently available. Alectinib is a secondgeneration ALK TKI, not recognized by ABCB1 $(75,76)$, which demonstrated significant IC activity in crizotinibrefractory patients. In a phase I/II study, alectinib led to an objective response in $52 \%$ of patients with $\mathrm{BMs}$ at baseline and a complete response (CR) in $29 \%$ of cases (77). In a phase II study, CNS DCR with alectinib was $83 \%$ (95\% CI: 74-91\%) and ORR 57\% (95\% CI: 39-74\%) with a higher probability for this drug of non-CNS progression compared with crizotinib (78). In another phase II study, CNS DCR with alectinib was 100\% (95\% CI: $79-100 \%)$ and ORR 67\% among patients with untreated BMs (79). The ALEX study is a phase III trial conducted on 303 patients with non-pretreated advanced ALK-rearranged NSCLC, randomized to receive alectinib (600 $\mathrm{mg}$ twice a day) or crizotinib. Alectinib was significantly superior to crizotinib in terms of TTIP (HR 0.16, 95\% CI: 0.10-0.28, $\mathrm{P}<0.001$ ). A CNS response occurred in $81 \%$ and $50 \%$ of patients with baseline measurable BMs $(n=43)$, respectively with alectinib (95\% CI: 58-95) and crizotinib (95\% CI: 28-72). The CNS efficacy of alectinib resulted in a large PFS benefit (25.7 versus 10.4 months, respectively with alectinib and crizotinib; HR 0.50, 95\% CI: $0.36-0.70, \mathrm{P}<0.001)(80)$. 
Alectinib also appeared active in ALK-positive NSCLC patients with leptomeningeal metastases pretreated with crizotinib and ceritinib (81). The latter is a secondgeneration ALK inhibitor that provided evidence of CNS antitumor activity in crizotinib-pretreated patients in whom IC ORR was $45 \%$ (95\% CI: 23-68\%) despite the drug being an ABCB1 substrate (82). Ceritinib (750 mg daily) was compared with chemotherapy as a first-line treatment for patients with advanced NSCLC and ALK translocation. ASCEND-4 is a randomized phase III study of 376 patients, 44 with baseline measurable BMs. The IC response among the ceritinib recipient patients was $73 \%$ (95\% CI: 49-89\%) versus $27 \%$ (95\% CI: $10-50 \%)$ among those receiving chemotherapy and the median PFS was 10.7 versus 6.7 months (HR 0.70, 95 \% CI: 0.44-1.12) for patients with BMs receiving ceritinib and chemotherapy, respectively (83). The phase II study ASCEND-7 (NCT02336451) in which the efficacy of ceritinib is evaluated in patients with metastatic brain NSCLC and/or leptomeninges harboring rearrangement of ALK, has recently been completed. Another second-generation ALK TKI is brigatinib which, in a phase I/II study of patients pretreated or not with crizotinib and with or without BMs, demonstrated an ORR IC of $50 \%$ in patients with BMs (84). The ALTA phase II randomized trial in crizotinib-pretreated patients divided into two groups, A with $90 \mathrm{mg}$ of brigatinib daily and B with $90 \mathrm{mg}$ a day for a week followed by $180 \mathrm{mg}$ a day, showed ORRs of $42 \%$ and $67 \%$ in patients with BMs in groups A and B, respectively (85). Among patients with ALK-positive NSCLC who have not previously received an ALK inhibitor, IC ORR in patients with measurable BMs was higher among those who received brigatinib (78\%, 95\% CI: 52-94\%) than those who received crizotinib (29\%, 95\% CI: $11-52 \%)$ in the randomized phase III ALTA-1L study in which, unlike the ALEX study, previous chemotherapy and crossover were allowed (86). Lorlatinib is a third-generation ALK inhibitor, developed to overcome resistance to first- and second-generation ALK TKIs and to improve brain penetration. In a phase I study, lorlatinib was active in the CNS, inducing IC response in $42 \%$ (95\% CI: $20-67 \%$ ) of heavily pretreated ALK-positive patients with measurable BMs. In the study it was found that the average ratio of CSF/plasma concentrations of lorlatinib was 0.75 , far exceeding the 0.03 ratio reported with crizotinib (87). IC ORRs of $68 \%$ (95\% CI: $50-82 \%$ ) and $48 \%$ (95\% CI: $37-59 \%)$ subsequently emerged with lorlatinib in patients pretreated with crizotinib and at least two ALK inhibitors respectively in a phase II study (88). The randomized phase
III study CROWN (NCT03052608), which compares lorlatinib with crizotinib as a first-line treatment for ALKactivated NSCLC is currently recruiting patients, even with BMs. Another novel ALK inhibitor is entrectinib, evaluated in two phase I, ALKA-372-001 and STARTRK-1 studies: of the 25 evaluable phase II-eligible patients, $32 \%(n=8 / 25)$ had brain disease and there was a response in $63 \%$ of them $(\mathrm{n}=5 / 8)$ of which one was a patient with ALK-rearranged NSCLC (89). STARTRK-2 is a phase II study with entrectinib (600 $\mathrm{mg}$ daily) for patients with solid tumors and several gene alterations, including ALK rearrangement. An IC response was reported in $50 \%$ of patients (90). The ALK inhibitor ensartinib was tested in a phase I/II study in which an ORR IC of $64.3 \%$ was achieved in 14 ALK-positive NSCLC patients with brain target lesions; the IC DCR was $92.9 \%$ (91). The randomized phase III study eXalt3 (NCT02767804) comparing ensartinib (225 mg daily) and crizotinib in ALK-positive NSCLC patients pretreated or not with chemotherapy, with or without BMs, is ongoing. In a meta-analysis on ALK inhibitors in NSCLC patients with BMs, Zhang et al. reported favorable intracranial activity with an overall IC ORR of 48\% (95\% CI: 32-63\%) (79\% for alectinib, $48 \%$ for brigatinib, $45 \%$ for ceritinib and $18 \%$ for crizotinib). From five randomized trials with ALK inhibitors versus chemotherapy, the pooled HR for IC PFS was 0.52 (95\% CI: 0.36-0.75) (92). Table 2 lists selected trials with ALK TKIs for NSCLC with BMs.

\section{With ROS-1 rearrangement}

Crizotinib was shown to be active in NSCLC patients with ROS-1 rearrangement. In an expansion cohort of the phase I study of crizotinib 50 patients were enrolled, most of whom had received first one or two lines of therapy. ORR was $72 \%$ with a median response duration of 17.6 months and a PFS of 19.2 months (94). These results are consistent with the results of the retrospective study EUROS1, which included 32 NSCLC patients positive for ROS1 , treated with crizotinib as first-, second- or third-line forward. In the 29 evaluable patients for the response, RR was $80 \%$ and the median PFS was 9.1 months (95). In the absence of direct comparison data between crizotinib and chemotherapy in these specific patients and, as crizotinib activity data come predominantly from patients pretreated with chemotherapy, the high activity demonstrated by crizotinib in terms of RR and the prolonged response duration are elements that support its use in the frontline in the ROS1-positive subgroup. With regard to brain 
Table 2 CNS ORRs and DCRs from selected trials with ALK TKIs for advanced NSCLC

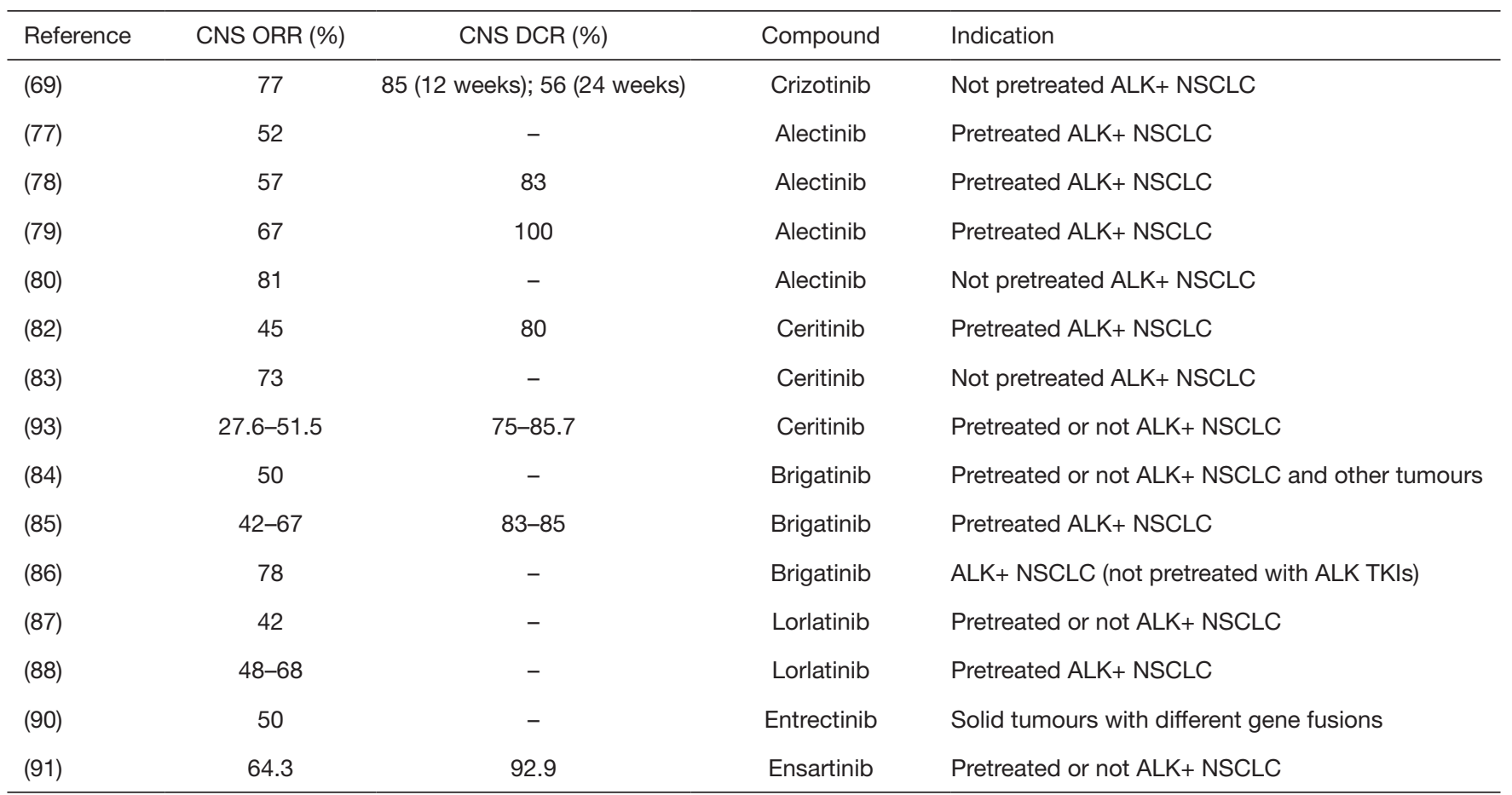

ALK TKIs, anaplastic lymphoma kinase tyrosine kinase inhibitors; CNS ORR, central nervous system objective response rate; DCR, disease control rate; NSCLC, non-small cell lung cancer.

Table 3 CNS ORRs and DCRs from selected trials with TKIs for NSCLC and gene alterations other than EGFR and ALK

\begin{tabular}{lccll}
\hline Reference & CNS ORR $(\%)$ & CNS DCR $(\%)$ & Compound & Indication \\
\hline$(97)$ & 73.9 & - & Crizotinib & Pretreated ROS1+ NSCLC \\
$(99)$ & 25 & 63 & Ceritinib & Pretreated ROS1+ NSCLC \\
$(87)$ & 60 & - & Lorlatinib & Pretreated or not ROS1+ NSCLC \\
$(100)$ & 55 & - & Entrectinib & Pretreated or not ROS1+ NSCLC \\
$(101)$ & 66.6 & - & Entrectinib & Pretreated or not NTRK+ NSCLC
\end{tabular}

CNS ORR, central nervous system objective response rate; DCR, disease control rate; NSCLC, non-small cell lung cancer; NTRK, neurotrophic tyrosine receptor kinase; ROS-1, c-ros oncogene 1; TKIs, tyrosine kinase inhibitors.

involvement, there is still wide variability in the reported incidence of BMs for ROS1-rearranged NSCLC (95-97). In a retrospective study by Patil et al., BMs for therapynaïve, stage IV ROS1- and ALK-positive NSCLC were present with an incidence of $36 \%$ and $34 \%$, respectively. Median PFS times for ROS1- and ALK-positive patients were 11 and 8 months, respectively $(\mathrm{P}=0.304)$ (98). Clinical trials with TKIs for ROS1-positive NSCLC with BMs are listed in Table 3. A phase II study evaluated crizotinib in 127 patients with ROS1-positive NSCLC treated from the first to the subsequent lines of therapy. Of these, 23 had BMs at diagnosis. In them, ORR was $73.9 \%$ (71.2\% in those without baseline BMs) and the median PFS 10.2 months (18.8 months in those without baseline BMs). Globally, the responses were lasting with a median duration of 19.7 months (97). Behind the duration of crizotinib-induced response in ROS1-translocated patients, various factors have been called into question, in particular the closer link to ROS-1 than ALK against which it has a diminished potency (102-104). Other inhibitors have been evaluated 
in this population. Ceritinib was active in patients heavily pretreated in a phase II study of 32 patients enrolled, 8 of whom with BMs. IC ORR was $25 \%$ with an IC disease control in $63 \%$ of patients (99). In a phase I study, lorlatinib showed IC activity in patients with ROS1-positive NSCLC: $3(60 \%)$ of 5 patients with measurable BMs had CNS responses, including 2 progressed to crizotinib (87). From an integrated analysis of three clinical studies (ALKA-372001, STARTRK-1 and STARTRK-2) with entrectinib in 53 ROS1-rearranged NSCLC patients, among the 23 patients with baseline brain disease, ORR was $55 \%$ with a median duration of response (DOR) of 12.9 months (100). More generally, entrectinib was associated with longer time-totreatment discontinuation (TTD) and PFS in NSCLC patients with ROS-1 rearrangement versus a matched realworld crizotinib population (105). A phase I study showed IC activity by another inhibitor, ropotrectinib, in TKIrefractory ROS1-positive patients, also with BMs. 29 were the ROS1-positive NSCLC patients mostly TKI pretreated $(n=19)$ : in them, ORR was $11 \%$ versus $70 \%$ of TKI- naïve patients and IC activity was observed (106).

\section{With other targetable gene alterations}

Rearrangement of the neurotrophic tyrosine receptor kinase (NTRK) gene with relative expression of a Trk tyrosine kinase fusion protein is found in approximately $3 \%$ of NSCLCs (107). From integrated efficacy data (ALKA-372001, STARTRK-1 and STARTRK-2 studies) in NTRKpositive NSCLC patients with BMs $(n=6)$, entrectinib induced an IC response in 4 patients and a disease stability in another patient (101) (Table 3). Other inhibitors evaluated include ropotrectinib (106) and larotrectinib, a pan-TRK TKI that achieved a $78 \% \mathrm{RR}$ in a phase I study with 55 NTRK-positive solid tumors (5 NSCLC patients) (108). A phase II study (NCT02576431) with larotrectinib in patients with NTRK-positive solid tumors (BMs are allowed) is currently ongoing. BRAF mutations are present in $2-4 \%$ of NSCLCs and are among the new therapeutic targets (109). Unlike other BRAF-guided cancers, mutational variants different from the classic V600E represent half of the BRAF mutations in NSCLC (110). Preclinical studies suggest that the resulting kinase activity varies according to the type of BRAF mutation (111-113). This is supported by case reports and small series that show distinct activity by BRAF inhibitors in lung cancers with class I, II or III mutations $(4,114,115)$. NSCLC patients with class II and III BRAF mutations were more likely to have $\mathrm{BM}(\mathrm{P} \leq 0.001)$ than those with class I mutation, as reported in a retrospective analysis by Dagogo-Jack et al. (116). Even the survival was shorter than class I. Together, the BRAF inhibitor dabrafenib $(150 \mathrm{mg}$ twice daily) and the MEK inhibitor trametinib ( $2 \mathrm{mg}$ per day) have demonstrated clinical activity in 57 pretreated BRAF V600E-mutated NSCLC patients in a phase II study, with 67\% RR and median PFS and OS of 10.2 and 18.2 months, respectively (117). Similar outcomes were reported in 36 patients with untreated BRAF-V600E-mutant metastatic NSCLC (118). Two patients had baseline BMs as nontarget lesions. For both patients, an overall best response of PR was reported. There have been some reports in patients with brain disease (119) but further clinical validation is necessary.

\section{Systemic therapy versus local radiotherapy or combination strategies for BMs from oncogene- addicted NSCLC}

Whole brain radiotherapy (WBRT) and stereotactic radiosurgery (SRS) are among the standard therapies for patients with BMs (120). However, numerous clinical trials demonstrated the efficacy of targeted drugs in the CNS for patients with oncogene-addicted NSCLC. Hence the question, still open, whether to use radiotherapy and above all with what timing with respect to systemic therapy. In a retrospective comparison of erlotinib and radiotherapy for NSCLC patients with EGFR mutation and BMs, Gerber et al. found a longer TTIP with WBRT versus erlotinib upfront (median, 24 versus 16 months, $\mathrm{P}=0.04$ ), with no difference in OS between the two groups. Patients treated with SRS, on the other hand, had longer OS compared to those treated with erlotinib (median, 64 months, $\mathrm{P}=0.004)$ (121). In another retrospective analysis by Magnuson et al., patients were treated with SRS or WBRT followed by EGFR TKI or with EGFR TKI followed by SRS or WBRT at IC progression. The median OS for SRS, WBRT and EGFR TKI therapy was 46, 30 and 25 months, respectively $(\mathrm{P}<0.001)$. SRS followed by EGFR TKI resulted in the longest OS and allowed patients to defer WBRT (122). Upfront brain radiotherapy improved IC PFS $(\mathrm{P}=0.03)$ and OS $(\mathrm{P}=0.05)$ compared with EGFR TKIs alone in a metaanalysis by Soon et al. in EGFR-mutated NSCLC (123). Li et al. confirmed better OS with upfront WBRT for this type of patients (124). Brain radiotherapy failed to demonstrate a significant association with survival in EGFR-mutated patients $(\mathrm{P}=0.643)$ and the timing of the treatment was not 
significantly related to $\mathrm{OS}(\mathrm{P}=0.246)$ in a retrospective study by Liu et al. (125). Preclinical studies have demonstrated the synergistic effect of TKIs combined with radiotherapy (126). The latter increases EGFR expression while TKIs inhibit radiation-induced DNA damage repair (127). They block the expression of RAD51, a protein involved in DNA repair mechanisms, inhibit phosphorylation of EGFR and enhance apoptosis $(126,128)$. Furthermore, WBRT damages the BBB facilitating the penetration of TKIs in the CNS (129). In the pooled analysis of the LUX-Lung 3 and LUX-Lung 6 trials, the benefit in PFS given by afatinib in patients with BMs, was greater in those undergoing previous WBRT (13.8 versus 4.7 months with afatinib and chemotherapy respectively, HR $0.37,95 \%$ CI: $0.12-1.17, \mathrm{P}=0.0767$ ) compared to those not subjected to WBRT (6.9 versus 5.4 months, HR 0.62, 95\% CI: $0.28-1.36, \mathrm{P}=0.2222$ ) (48). In a phase II study with erlotinib plus WBRT for NSCLC patients with BMs, ORR was $86 \%$ and OS 11.8 months. Median survival was 19.1 months for EGFR-mutated patients (130). Gefitinib plus WBRT gave a higher ORR (64.4\%) and a significant improvement in OS (23.4 months) compared retrospectively with gefitinib alone (ORR 26.7\%, $\mathrm{P}<0.001$; OS 14.83 months, $\mathrm{P}=0.002$ ) (131). AZD3759 combined with radiotherapy enhanced antitumor activity in BMs from EGFR-mutated NSCLC (132). Wang et al. indicated that brain radiotherapy could result in a lower IC PFS while EGFR-mutated patients receiving upfront or concurrent brain radiotherapy followed by TKIs had a longer OS than the upfront TKIs group $(\mathrm{P}=0.035)$ (133). In a recent retrospective study published by Chen $e t$ al. on EGFRmutated patients with NSCLC and BMs, the median OS was 14.3 months (95\% CI: $9.5-18.3$ months) in the TKI plus WBRT group and 2.3 months (95\% CI: 2-2.6 months) in the TKI group alone (134). TKIs included gefitinib, erlotinib, afatinib and osimertinib. However, Ke et al. did not report a significant difference in OS between the group treated with only EGFR TKI compared to that treated with EGFR TKI plus WBRT; just as there was no statistical difference in OS using radiotherapy before or after (135). TTIP was longer in the EGFR TKI group plus WBRT than in the EGFR TKI group $(\mathrm{P}=0.001)$. Concurrent EGFR TKI (gefitinib, erlotinib or icotinib) and WBRT improved IC PFS compared with EGFR TKI alone $(\mathrm{P}=0.015)$ but not $\mathrm{OS}(\mathrm{P}=0.756)$ in a retrospective study by $\mathrm{He}$ et al. (136). Compared to TKIs alone, the addition of WBRT to them was not associated with a superior benefit in terms of OS $(\mathrm{P}=0.049)$ and IC PFS $(\mathrm{P}=0.232)$ in NSCLC with EGFR mutation and BMs (137). This study included asymptomatic and symptomatic BMs.
It is clear that all these often conflicting data are the result of meta-analysis and non-controlled studies characterized by heterogeneous patient populations and inadequate statistical power in many cases. Similar analyses concern patients with oncogene-addicted NSCLC with molecular alterations other than EGFR. Doherty et al. reported that WBRT for EGFR- and ALK-guided NSCLC BMs is associated with longer TTIP compared to SRS or only TKI $(\mathrm{P}=0.0038)$, with no differences in OS $(\mathrm{P}=0.67)$. This is also a retrospective evaluation and the authors suggest that WBRT may be delayed in some patients (138). The role of radiotherapy in the management of EGFR- or ALK-mutated NSCLC treated with TKIs was explored in a retrospective study by Borghetti et al., in which SRS positively influenced OS (139). The lack of randomized studies in this peculiar clinical context is striking. The BRAIN trial, the first openlabel, phase III, head-to-head study that compared EGFR TKI (icotinib) with WBRT in 158 patients with EGFRmutated NSCLC and BMs (63) was an exception (Table 1). Icotinib (125 mg three times a day) achieved a higher IC PFS than WBRT plus chemotherapy (10 versus 4.8 months, HR 0.56, 95\% CI: 0.36-0.90, $\mathrm{P}=0.014$ ). Similarly, the median PFS was longer in the icotinib group than in the WBRT group (6.8 versus 3.4 months, HR 0.44, $95 \%$ CI: $0.31-0.63, \mathrm{P}<0.0001)$. IC ORR was $65 \%$ for icotinib and $37 \%$ for WBRT $(\mathrm{P}=0.001)$. However, OS was not statistically different between the two groups: 18.0 versus 20.5 months for the icotinib and WBRT arm respectively (HR 0.93, 95\% CI: 0.60-1.44, $\mathrm{P}=0.734$ ), probably due to the high crossover rate from WBRT to icotinib (63). TRACTS (NCT01763385) is a randomized phase II study investigating erlotinib with concurrent brain radiotherapy and secondary brain radiotherapy after recurrence with erlotinib. However, the study also envisages the use of WBRT and not of SRS as a radiotherapy treatment.

\section{Conclusions}

Over the years, a specific histological characterization of NSCLC and the recognition of certain genomic alterations has made it possible to identify some subgroups of patients who are sensitive or resistant to specific treatments, in addition to paving the way towards new therapies being evaluated. The most frequent EGFR mutations are the deletion of exon 19 and the L858R point mutation of exon 21 , which together represent about $90 \%$ of cases. The remaining $10 \%$ of EGFR mutations is represented by not common mutations affecting exons 18-21 (140). EGFR 
TKIs are the treatment of choice for the first-line in patients with advanced NSCLC and classic EGFR mutations. In the joint analysis of the LUX-Lung 3 and LUX-Lung 6 studies, the greatest benefit with afatinib was observed in patients with exon 19 deletion whereas in patients with the L858R mutation there was no benefit (16). These data, however consistent with similar available evidence for gefitinib and erlotinib, suggest biological and clinical differences between the two mutations but do not constitute a criterion for the preferential choice of one inhibitor over another (141-143). Comparative studies of TKIs were conducted in the treatment of patients with EGFR-mutated NSCLC. The randomized phase III study CTONG009 that compared erlotinib with gefitinib (amended to include patients with exon 19 mutation in addition to those with exon 21 mutation) in the first- and second-line, did not show significant differences between the two arms in terms of RR, PFS and OS (144). To these data are added those of the non-inferiority phase III randomized study WJOG5108L which compared gefitinib and erlotinib in pretreated patients without demonstrating a significant difference in OS in the two arms (145). The LUX-Lung 7 study with afatinib in first-line versus gefitinib in patients with classical EGFR mutation demonstrated superiority of the former in terms of PFS $(\mathrm{P}=0.017)$ but not of OS $(\mathrm{P}=0.285)(49,146)$. The randomized phase III ARCHER 1050 study compared the second-generation inhibitor dacomitinib with gefitinib as first-line treatment in patients with classical EGFR mutation (BMs were a study exclusion criterion). Both PFS $(\mathrm{P}<0.0001)$ and $\mathrm{OS}$ $(\mathrm{P}=0.0438)$ were significantly better with dacomitinib $(147,148)$. Finally, the randomized phase III study FLAURA compared osimertinib with erlotinib and gefitinib in the first-line of therapy, again in patients with classical EGFR mutation, demonstrating a significant advantage in PFS $(\mathrm{P}<0.001)$ and $\mathrm{OS}(\mathrm{P}=0.0462)$ with osimertinib $(149,150)$. For IC PFS, patients with L858R mutation could benefit more from the combination of EGFR TKI plus radiotherapy although this result, which is derived from a meta-analysis, did not reach statistical significance (151). Some factors can be considered: BMs were particularly associated with deletion of exon 19 in a retrospective study of over 1,000 patients, in agreement with the results of $\mathrm{Li}$ et al. in $2015(152,153)$. Another study reported a localization of BMs with L858R mutation closer to the brain surface (154). Furthermore, the concentration of drug that influences IC PFS differed between EGFR mutations 19 and 21 in a study by Okuda $e t$ al. in which it was found that, unlike the deletion of exon 19, IC PFS of mutated L858R patients was significantly different between low and high concentrations of gefitinib (155). Since radiation therapy alters BBB integrity by increasing CSF concentration of TKIs, this may explain why the mutation in exon 21 promotes combined therapy. On the other hand, deletion of exon 19 is associated with prolonged survival in BMs from NSCLC (156). Traditionally, WBRT is a standard treatment option for patients with BMs $(157,158)$. It has been associated with higher incidence of radiationrelated toxicity than SRS (159). The latter directs high doses of radiation onto the tumor volume with millimeter precision, saving as much as possible the surrounding healthy tissues and reducing the treatment duration $(160,161)$. Brown et al. found that among patients with 1-3 BMs, SRS alone was in lower cognitive impairment than SRS combined with WBRT. In the absence of a difference in OS, this suggests that for those patients the SRS alone may be the preferred strategy (162). In a retrospective study by Wang et al., the median OS of the SRS group was longer than in the WBRT group, but this finding did not appear significant either in patients with asymptomatic BMs or with symptomatic BMs (133). Cai et al. reported 10 months of median PFS and 16 months of median OS in 7 NSCLC patients with BMs and EGFR mutation, treated with SRS and concurrent gefitinib (163). In addition, Yamamoto et al. have suggested that SRS in patients with up to $10 \mathrm{BMs}$ (largest tumor $<10 \mathrm{~mL}$ in volume and $<3 \mathrm{~cm}$ in longest diameter; total cumulative volume $\leq 15 \mathrm{~mL}$ ) could be a suitable alternative with fewer side effects than WBRT (164). Immediate SRS but not WBRT has been associated with longer survival in a recently published study by Lee et al. on EGFR-mutated patients with BMs (165). Today, thanks to SRS and new drugs it is possible to delay WBRT which is associated with adverse effects and may not improve the survival or quality of life of patients $(166,167)$. The role of radiotherapy in patients receiving osimertinib requires further research. CNS response to osimertinib was observed independently of previous brain radiotherapy (59). Osimertinib gave $80 \%$ CNS DCR and $53.3 \%$ ORR in NSCLC patients in real-world setting (168). In this study CNS DCR was higher in patients with EGFR T790M +/ exon19del mutations than in those with EGFR T790M +/ exon21 L858R mutations but there was no statistical difference between the two groups, not even in terms of CNS ORR. This was consistent with the results of the overall population of the AURA2 study (169) and with studies that reported greater efficacy of EGFR TKIs in 
patients with deletion of exon 19 rather than the L858R mutation of exon 21 (143). However, the emergence of the T790M resistance mutation is comparatively rarer in the CNS, suggesting that divergent evolution and different resistance mechanisms may occur (170-172). Lazertinib is among the mutant-selective EGFR inhibitors with a high CNS efficacy. Lazertinib is a third-generation inhibitor not recognized by ABCG2 and a weak substrate of $A B C B 1$ that, compared in vivo to equimolar concentrations, produced better tumor regression than osimertinib (173). Yun et al. have proved potent $\mathrm{BBB}$ penetration by lazertinib and potential toxicity advantage (173). A total of 105 NSCLC patients with acquired resistance to EGFR TKIs with or without BMs were enrolled in a phase I/II study and treated with lazertinib. ORRs were $64 \%$ and $67 \%$ in evaluable patients $(n=91)$ and in T790M-positive patients $(n=76)$, respectively. In patients with $\mathrm{BMs}(\mathrm{n}=9)$, ORR was $56 \%(64)$ (Table 1). NSCLC represents a heterogeneous disease that includes an increasing number of biologically and clinically distinct molecular subtypes $(174,175)$. Their identification and subsequent development of targeted therapies have transformed the natural history of oncogene-addicted NSCLC. With increased patient survival, an increased risk of developing BMs was also observed. This has led to a growing interest in optimizing local disease control. The use of biological agents combined with radiotherapy requires well-designed, multi-institutional prospective assessments that can validate findings derived in most cases from retrospective studies from which no definitive conclusions can be drawn. Even trials that help to better define the optimal sequence of brain radiotherapy and systemic TKI therapy are also necessary. One of these is the phase II multiple-arm study ASCEND-7 (NCT02336451). Evaluation of the IC response in 28, 29, 7 and 33 patients in the respective arms (arm 1: previous brain radiotherapy and previous ALK TKI, arm 2: previous ALK TKI but not brain radiotherapy, arm 3: previous brain radiotherapy but not ALK TKI , arm 4: no previous brain radiotherapy nor ALK TKI) having baseline measurable BMs showed IC ORRs of $39.3 \%, 27.6 \%, 28.6 \%$ and $51.5 \%$, and IC DCRs of $75.0 \%, 82.8 \%, 85.7 \%$ and $75.8 \%$, respectively (93). Tools that predict the survival of patients with NSCLC and BMs can facilitate the choice of personalized treatment and be used to stratify patients enrolled in future clinical trials (176-178). However, following the progress of radiotherapy and the current availability of new drugs, some factors included in these scores may be less prognostic for patients with BMs and oncogene-addicted disease. Certainly, the timing and modalities of brain radiotherapy in patients with lung cancer and gene alterations should be determined on an individual basis and with a multidisciplinary approach, even in symptomatic patients usually excluded from clinical trials.

\section{Acknowledgments}

None.

\section{Footnote}

Conflicts of Interest: C Gridelli received honoraria as speaker bureau and advisory board member from Astra Zeneca, BMS, MSD, Roche. M Muto received honoraria as speaker bureau from Astra Zeneca. G Colantuoni received honoraria as advisory board member from Lilly, Novartis, Pfizer. The other authors have no conflicts of interest to declare.

Ethical Statement: The authors are accountable for all aspects of the work in ensuring that questions related to the accuracy or integrity of any part of the work are appropriately investigated and resolved.

\section{References}

1. Paez JG, Jänne PA, Lee JC, et al. EGFR mutations in lung cancer: correlation with clinical response to gefitinib therapy. Science 2004;304:1497-500.

2. Kwak EL, Bang YJ, Camidge DR, et al. Anaplastic lymphoma kinase inhibition in non-small cell lung cancer. N Engl J Med 2010;363:1693-703.

3. Shaw AT, Solomon BJ. Crizotinib in ROS1-rearranged non-small cell lung cancer. N Engl J Med 2015;372:683-4.

4. Planchard D, Besse B, Groen HJM, et al. Dabrafenib plus trametinib in patients with previously treated BRAF(V600E)-mutant metastatic non-small cell lung cancer: an open-label, multicentre phase 2 trial. Lancet Oncol 2016;17:984-93.

5. Wang BX, Ou W, Mao XY, et al. Impacts of EGFR mutation and EGFR-TKIs on incidence of brain metastases in advanced non-squamous NSCLC. Clin Neurol Neurosurg 2017;160:96-100.

6. Rangachari D, Yamaguchi N, VanderLaan PA, et al. Brain metastases in patients with EGFR-mutated or ALKrearranged non-small cell lung cancers. Lung Cancer 2015;88:108-11. 
7. Mok TS, Wu YL, Thongprasert S, et al. Gefitinib or carboplatin-paclitaxel in pulmonary adenocarcinoma. $\mathrm{N}$ Engl J Med 2009;361:947-57.

8. Han JY, Park K, Kim SW, et al. First-SIGNAL: first-line single-agent Iressa versus gemcitabine and cisplatin trial in never-smokers with adenocarcinoma of the lung. J Clin Oncol 2012;30:1122-8.

9. Mitsudomi T, Morita S, Yatabe Y, et al. Gefitinib versus cisplatin plus docetaxel in patients with non-small cell lung cancer harbouring mutations of the epidermal growth factor receptor (WJTOG3405): an open label, randomised phase 3 trial. Lancet Oncol 2010;11:121-8.

10. Maemondo M, Inoue A, Kobayashi K, et al. Gefitinib or chemotherapy for non-small cell lung cancer with mutated EGFR. N Engl J Med 2010;362:2380-8.

11. Zhou C, Wu YL, Chen G, et al. Erlotinib versus chemotherapy as first-line treatment for patients with advanced EGFR mutation-positive non-small cell lung cancer (OPTIMAL, CTONG-0802): a multicentre, open-label, randomised, phase 3 study. Lancet Oncol 2011;12:735-42.

12. Rosell R, Carcereny E, Gervais R, et al. Erlotinib versus standard chemotherapy as first-line treatment for European patients with advanced EGFR mutation-positive non-small cell lung cancer (EURTAC): a multicentre, open-label, randomised phase 3 trial. Lancet Oncol 2012;13:239-46.

13. Sequist LV, Yang JC, Yamamoto N, et al. Phase III study of afatinib or cisplatin plus pemetrexed in patients with metastatic lung adenocarcinoma with EGFR mutations. J Clin Oncol 2013;31:3327-34.

14. $\mathrm{Wu} \mathrm{YL}, \mathrm{Zhou} \mathrm{C}, \mathrm{Hu} \mathrm{CP}$, et al. Afatinib versus cisplatin plus gemcitabine for first-line treatment of Asian patients with advanced non-small cell lung cancer harbouring EGFR mutations (LUX-Lung 6): an open-label, randomised phase 3 trial. Lancet Oncol 2014;15:213-22.

15. Pao W, Iafrate AJ, Su Z. Genetically informed lung cancer medicine. J Pathol 2011;223:230-40.

16. Yang JC, Wu YL, Schuler M, et al. Afatinib versus cisplatin-based chemotherapy for EGFR mutation-positive lung adenocarcinoma (LUX-Lung 3 and LUX-Lung 6): analysis of overall survival data from two randomised, phase 3 trials. Lancet Oncol 2015;16:141-51.

17. Yang JC, Sequist LV, Geater SL, et al. Clinical activity of afatinib in patients with advanced non-small cell lung cancer harbouring uncommon EGFR mutations: a combined post-hoc analysis of LUX-Lung 2, LUX-Lung 3, and LUX-Lung 6. Lancet Oncol 2015;16:830-8.
18. Yang CH, Yu CJ, Shih JY, et al. Specific EGFR mutations predict treatment outcome of stage IIIB/IV patients with chemotherapy-naive non-small cell lung cancer receiving first-line gefitinib monotherapy. J Clin Oncol 2008;26:2745-53

19. Sequist LV, Martins RG, Spigel D, et al. First-line gefitinib in patients with advanced non-small cell lung cancer harboring somatic EGFR mutations. J Clin Oncol 2008;26:2442-9.

20. De Pas T, Toffalorio F, Manzotti M, et al. Activity of epidermal growth factor receptor-tyrosine kinase inhibitors in patients with non-small cell lung cancer harboring rare epidermal growth factor receptor mutations. J Thorac Oncol 2011;6:1895-901.

21. Wu JY, Yu CJ, Chang YC, et al. Effectiveness of tyrosine kinase inhibitors on "uncommon" epidermal growth factor receptor mutations of unknown clinical significance in non-small cell lung cancer. Clin Cancer Res 2011;17:3812-21.

22. Lynch TJ, Bell DW, Sordella R, et al. Activating mutations in the epidermal growth factor receptor underlying responsiveness of non-small cell lung cancer to gefitinib. N Engl J Med 2004;350:2129-39.

23. Watanabe S, Minegishi Y, Yoshizawa H, et al. Effectiveness of gefitinib against non-small cell lung cancer with the uncommon EGFR mutations G719X and L861Q.J Thorac Oncol 2014;9:189-94.

24. Eichler AF, Kahle KT, Wang DL, et al. EGFR mutation status and survival after diagnosis of brain metastasis in non-small cell lung cancer. Neuro Oncol 2010;12:1193-9.

25. Lee HL, Chung TS, Ting LL, et al. EGFR mutations are associated with favorable intracranial response and progression-free survival following brain irradiation in non-small cell lung cancer patients with brain metastases. Radiat Oncol 2012;7:181.

26. Park SJ, Kim HT, Lee DH, et al. Efficacy of epidermal growth factor receptor tyrosine kinase inhibitors for brain metastasis in non-small cell lung cancer patients harboring either exon 19 or 21 mutation. Lung Cancer 2012;77:556-60.

27. Heon S, Yeap BY, Lindeman NI, et al. The impact of initial gefitinib or erlotinib versus chemotherapy on central nervous system progression in advanced non-small cell lung cancer with EGFR mutations. Clin Cancer Res 2012;18:4406-14.

28. Porta R, Sanchez-Torres JM, Paz-Ares L, et al. Brain metastases from lung cancer responding to erlotinib: the importance of EGFR mutation. Eur Respir J 
2011;37:624-31.

29. Togashi Y, Masago K, Fukudo M, et al. Cerebrospinal fluid concentration of erlotinib and its active metabolite OSI420 in patients with central nervous system metastases of non-small cell lung cancer. J Thorac Oncol 2010;5:950-5.

30. Togashi Y, Masago K, Masuda S, et al. Cerebrospinal fluid concentration of gefitinib and erlotinib in patients with non-small cell lung cancer. Cancer Chemother Pharmacol 2012;70:399-405.

31. Deng Y, Feng W, Wu J, et al. The concentration of erlotinib in the cerebrospinal fluid of patients with brain metastasis from non-small cell lung cancer. Mol Clin Oncol 2014;2:116-20.

32. Wu YL, Zhou C, Cheng Y, et al. Erlotinib as second-line treatment in patients with advanced non-small cell lung cancer and asymptomatic brain metastases: a phase II study (CTONG-0803). Ann Oncol 2013;24:993-9.

33. Ceresoli GL, Cappuzzo F, Gregorc V, et al. Gefitinib in patients with brain metastases from non-small cell lung cancer: a prospective trial. Ann Oncol 2004;15:1042-7.

34. Kashima J, Okuma Y, Miwa M, et al. Survival of patients with brain metastases from non-small cell lung cancer harboring EGFR mutations treated with epidermal growth factor receptor tyrosine kinase inhibitors. Med Oncol 2016;33:129.

35. Lee E, Keam B, Kim DW, et al. Erlotinib versus gefitinib for control of leptomeningeal carcinomatosis in non-small cell lung cancer. J Thorac Oncol 2013;8:1069-74.

36. Sekine A, Satoh H, Iwasawa T, et al. Prognostic factors for brain metastases from non-small cell lung cancer with EGFR mutation: influence of stable extracranial disease and erlotinib therapy. Med Oncol 2014;31:228.

37. Atagi S, Goto K, Seto T, et al. O1-10-2 Combined analysis of two phase II studies evaluating first-line erlotinib in NSCLC with EGFR mutation: JO22903/JO25567. Ann Oncol 2015;26:vii83.

38. <unknown>38. Lampson BL, Santos A, Janne PA, et al. Reduced-dose versus full-dose erlotinib for advanced EGFR-mutant non-small cell lung carcinoma (NSCLC): a retrospective analysis. J Clin Oncol 20415;33:8074.</ unknown>

39. Park K, Yu CJ, Kim SW, et al. First-line erlotinib therapy until and beyond response evaluation criteria in solid tumors progression in Asian patients with epidermal growth factor receptor mutation-positive nonsSmall cell lung cancer: the ASPIRATION study. JAMA Oncol 2016;2:305-12.

40. Sugawara S, Oizumi S, Minato K, et al. Randomized phase II study of concurrent versus sequential alternating gefitinib and chemotherapy in previously untreated nonsmall cell lung cancer with sensitive EGFR mutations: NEJ005/TCOG0902. Ann Oncol 2015;26:888-94.

41. Kanda S, Horinouchi H, Fujiwara Y, et al. Cytotoxic chemotherapy may overcome the development of acquired resistance to epidermal growth factor receptor tyrosine kinase inhibitors (EGFR-TKIs) therapy. Lung Cancer 2015;89:287-93.

42. Fan Y, Xu X, Xie C. EGFR-TKI therapy for patients with brain metastases from non-small cell lung cancer: a pooled analysis of published data. Onco Targets Ther 2014;7:2075-84.

43. Milton DT, Azzoli CG, Heelan RT, et al. A phase I/ II study of weekly high-dose erlotinib in previously treated patients with non-small cell lung cancer. Cancer 2006;107:1034-41.

44. Grommes C, Oxnard GR, Kris MG, et al. "Pulsatile" high-dose weekly erlotinib for CNS metastases from EGFR mutant non-small cell lung cancer. Neuro Oncol 2011;13:1364-9.

45. Kawamura T, Hata A, Takeshita J, et al. High-dose erlotinib for refractory leptomeningeal metastases after failure of standard-dose EGFRTKIs. Cancer Chemother Pharmacol 2015;75:1261-6.

46. Jackman DM, Cioffredi LA, Jacobs L, et al. A phase I trial of high dose gefitinib for patients with leptomeningeal metastases from non-small cell lung cancer. Oncotarget 2015;6:4527-36.

47. Hoffknecht P, Tufman A, Wehler T, et al. Efficacy of the irreversible ErbB family blocker afatinib in epidermal growth factor receptor (EGFR) tyrosine kinase inhibitor (TKI)-pretreated non-small cell lung cancer patients with brain metastases or leptomeningeal disease. J Thorac Oncol 2015;10:156-63.

48. Schuler M, Wu YL, Hirsh V, et al. First-line afatinib versus chemotherapy in patients with non-small cell lung cancer and common epidermal growth factor receptor gene mutations and brain metastases. J Thorac Oncol 2016;11:380-90.

49. Park K, Tan EH, O'Byrne K, et al. Afatinib versus gefitinib as first-line treatment of patients with EGFR mutationpositive non-small cell lung cancer (LUX-Lung 7): a phase 2B, open-label, randomised controlled trial. Lancet Oncol 2016;17:577-89.

50. Lim SM, Syn NL, Cho BC, et al. Acquired resistance to EGFR targeted therapy in non-small cell lung cancer: mechanisms and therapeutic strategies. Cancer Treat Rev 
2018;65:1-10.

51. Westover D, Zugazagoitia J, Cho BC, et al. Mechanisms of acquired resistance to first- and second-generation EGFR tyrosine kinase inhibitors. Ann Oncol 2018;29:110-9.

52. Kim ES. Olmutinib: first global approval. Drugs 2016;76:1153-7.

53. Jänne PA, Yang JC, Kim DW, et al. AZD9291 in EGFR inhibitor-resistant non-small cell lung cancer. N Engl J Med 2015;372:1689-99.

54. Sequist LV, Soria JC, Goldman JW, et al. Rociletinib in EGFR-mutated non-small cell lung cancer. N Engl J Med 2015;372:1700-9.

55. O'Kane GM, Barnes TA, Leighl NB. Resistance to epidermal growth factor receptor tyrosine kinase inhibitors, T790M, and clinical trials. Curr Oncol 2018;25:S28-37.

56. Ballard P, Yates JW, Yang Z, et al. Preclinical comparison of osimertinib with other EGFR-TKIs in EGFR-mutant NSCLC brain metastases models, and early evidence of clinical brain metastases activity. Clin Cancer Res 2016;22:5130-40.

57. Goss G, Tsai CM, Shepherd FA, et al. CNS response to osimertinib in patients with T790M-positive advanced NSCLC: pooled data from two phase II trials. Ann Oncol 2018;29:687-93.

58. Mok TS, Wu YL, Ahn MJ, et al. Osimertinib or platinumpemetrexed in EGFR T790M-positive lung cancer. N Engl J Med 2017;376:629-40.

59. Reungwetwattana T, Nakagawa K, Cho BC, et al. CNS response to osimertinib versus standard epidermal growth factor receptor tyrosine kinase inhibitors in patients with untreated EGFR-mutated advanced non-small cell lung cancer. J Clin Oncol 2018;36:3290-7.

60. Ahn MJ, Kim DW, Cho BC, et al. Activity and safety of AZD3759 in EGFR-mutant non-small cell lung cancer with CNS metastases (BLOOM): a phase 1, open-label, dose-escalation and dose-expansion study. Lancet Respir Med 2017;5:891-902.

61. Yang Z, Guo Q, Wang Y, et al. AZD3759, a BBBpenetrating EGFR inhibitor for the treatment of EGFR mutant NSCLC with CNS metastases. Sci Transl Med 2016;8:368ra172.

62. Yang JC, Cho BC, Kim DW, et al. Osimertinib for patients (pts) with leptomeningeal metastases (LM) from EGFRmutant non-small cell lung cancer (NSCLC): updated results from the BLOOM study. J Clin Oncol 2017;35:2020.

63. Yang JJ, Zhou C, Huang Y, et al. Icotinib versus whole- brain irradiation in patients with EGFR-mutant non-smallcell lung cancer and multiple brain metastases (BRAIN): a multicentre, phase 3, open-label, parallel, randomised controlled trial. Lancet Respir Med 2017;5:707-16.

64. Ahn MJ, Han JY, Kim SW, et al. Lazertinib, a 3rd generation EGFR-TKI, in patients with EGFR-TKI resistant NSCLC: updated results of phase I/II study. J Clin Oncol 2019;37:9037.

65. Shaw AT, Kim DW, Nakagawa K, et al. Crizotinib versus chemotherapy in advanced ALK-positive lung cancer. N Engl J Med 2013;368:2385-94.

66. Shaw AT, Kim DW, Mehra R, et al. Ceritinib in ALKrearranged non-small-cell lung cancer. N Engl J Med 2014;370:1189-97.

67. Solomon BJ, Mok T, Kim DW, et al. First-line crizotinib versus chemotherapy in ALK-positive lung cancer. N Engl J Med 2014;371:2167-77.

68. Solomon BJ, Kim DW, Wu YL, et al. Final overall survival analysis from a study comparing first-line crizotinib versus chemotherapy in ALK-mutation-positive non-small cell lung cancer. J Clin Oncol 2018;36:2251-8.

69. Solomon BJ, Cappuzzo F, Felip E, et al. Intracranial efficacy of crizotinib versus chemotherapy in patients with advanced ALK-positive non-small cell lung cancer: results from PROFILE 1014. J Clin Oncol 2016;34:2858-65.

70. Costa DB, Shaw AT, Ou SH, et al. Clinical experience with crizotinib in patients with advanced ALK-rearranged non-small cell lung cancer and brain metastases. J Clin Oncol 2015;33:1881-8.

71. Chun SG, Choe KS, Iyengar P, et al. Timmerman RD. Isolated central nervous system progression on crizotinib: an Achilles heel of non-small cell lung cancer with EML4ALK translocation? Cancer Biol Ther 2012;13:1376-83.

72. Costa DB, Kobayashi S, Pandya SS, et al. CSF concentration of the anaplastic lymphoma kinase inhibitor crizotinib. J Clin Oncol 2011;29:e443-5.

73. Peled N, Zach L, Liran O, et al. Effective crizotinib schedule for brain metastases in ALK rearrangement metastatic non-small cell lung cancer. J Thorac Oncol 2013;8:e112-3.

74. Gandhi L, Drappatz J, Ramaiya NH, et al. High-dose pemetrexed in combination with high-dose crizotinib for the treatment of refractory CNS metastases in ALKrearranged non-small cell lung cancer. J Thorac Oncol 2013;8:e3-5.

75. Tang SC, Nguyen LN, Sparidans RW, et al. Increased oral availability and brain accumulation of the ALK inhibitor crizotinib by co-administration of the P-glycoprotein 
(ABCB1) and breast cancer resistance protein (ABCG2) inhibitor elacridar. Int J Cancer 2014;134:1484-94.

76. Kodama T, Hasegawa M, Takanashi K, et al. Antitumor activity of the selective ALK inhibitor alectinib in models of intracranial metastases. Cancer Chemother Pharmacol 2014;74:1023-8.

77. Gadgeel SM, Gandhi L, Riely GJ, et al. Safety and activity of alectinib against systemic disease and brain metastases in patients with crizotinib-resistant ALK-rearranged non-small cell lung cancer (AF-002JG): results from the dose-finding portion of a phase 1/2 study. Lancet Oncol 2014;15:1119-28.

78. Ou SH, Ahn JS, De Petris L, et al. Alectinib in crizotinibrefractory ALK-rearranged non-small cell lung cancer: a Phase II global study. J Clin Oncol 2016;34:661-8.

79. Shaw AT, Gandhi L, Gadgeel S, et al. Alectinib in ALKpositive, crizotinib-resistant, non-small cell lung cancer: a single-group, multicentre, phase 2 trial. Lancet Oncol 2016;17:234-42.

80. Peters S, Camidge DR, Shaw AT, et al. Alectinib versus crizotinib in untreated ALK-positive non-small cell lung cancer. N Engl J Med 2017;377:829-38.

81. Gainor JF, Sherman CA, Willoughby K, et al. Alectinib salvages CNS relapses in ALK-positive lung cancer patients previously treated with crizotinib and ceritinib. J Thorac Oncol 2015;10:232-6.

82. Crinò L, Ahn MJ, De Marinis F, et al. Multicenter phase II study of whole-body and intracranial activity with ceritinib in patients with ALK-rearranged non-small cell lung cancer previously treated with chemotherapy and crizotinib: results from ASCEND-2. J Clin Oncol 2016;34:2866-73.

83. Soria JC, Tan DSW, Chiari R, et al. First-line ceritinib versus platinum-based chemotherapy in advanced ALKrearranged non-small-cell lung cancer (ASCEND-4): a randomised, open-label, phase 3 study. Lancet 2017;389:917-29.

84. Gettinger SN, Bazhenova LA, Langer CJ, et al. Activity and safety of brigatinib in ALK-rearranged non-small cell lung cancer and other malignancies: a single-arm, openlabel, phase 1/2 trial. Lancet Oncol 2016;17:1683-96.

85. Kim DW, Tiseo M, Ahn MJ, et al. Brigatinib in patients with crizotinib-refractory anaplastic lymphoma kinasepositive non-small cell lung cancer: a randomized, multicenter phaseII trial. J Clin Oncol 2017;35:2490-8.

86. Camidge DR, Kim HR, Ahn MJ, et al. Brigatinib versus crizotinib in ALK-positive non-small cell lung cancer. N Engl J Med 2018;379:2027-39.
87. Shaw AT, Felip E, Bauer TM, et al. Lorlatinib in nonsmall cell lung cancer with ALK or ROS1 rearrangement: an international, multicentre, open-label, single-arm firstin-man phase 1 trial. Lancet Oncol 2017;18:1590-9.

88. Solomon BJ, Shaw A, Ou SH, et al. Phase 2 study of lorlatinib in patients with advanced ALK+/ROS1+ nonsmall cell lung cancer. Presented at the IASLC 18th World Conference on Lung Cancer, October 15-18, Yokohama, Japan. Abstract 8573 .

89. Drilon A, Siena S, Ou SI, et al. Safety and antitumor activity of the multitargeted pan-TRK, ROS1, and ALK inhibitor entrectinib: combined results from two phase I trials (ALKA-372-001 and STARTRK-1). Cancer Discov 2017;7:400-9.

90. Available online: https://www.esmo.org/OncologyNews/Japan-Becomes-the-First-Country-to-ApproveEntrectinib (accessed October 19, 2019).

91. Horn L, Infante JR, Reckamp KL, et al. Ensartinib (X-396) in ALK-positive non-small cell lung cancer: results from a first-in-human phase I/II, multicenter study. Clin Cancer Res 2018;24:2771-9.

92. Zhang Z, Guo H, Lu Y, et al. Anaplastic lymphoma kinase inhibitors in non-small cell lung cancer patients with brain metastases: a meta-analysis. J Thorac Dis 2019;11:1397-409.

93. Available online: https://www.esmo.org/Oncology-News/ Ceritinib-Targets-Brain-Metastases-in-Patients-withALK-positive-NSCLC (accessed October 19, 2019).

94. Shaw AT, Ou SH, Bang YJ, et al. Crizotinib in ROS1rearranged non-small cell lung cancer. N Engl J Med 2014;371:1963-71.

95. Mazières J, Zalcman G, Crinò L, et al. Crizotinib therapy for advanced lung adenocarcinoma and a ROS1 rearrangement: results from the EUROS1 cohort. J Clin Oncol 2015;33:992-9.

96. Gainor JF, Tseng D, Yoda S, et al. Patterns of metastatic spread and mechanisms of resistance to crizotinib in ROS1-positive non-small cell lung cancer. JCO Precis Oncol 2017;2017.

97. Wu YL, Yang JC, Kim DW, et al. Phase II study of crizotinib in East Asian patients with ROS1-positive advanced non-small cell lung cancer. J Clin Oncol 2018;36:1405-11.

98. Patil T, Smith DE, Bunn PA, et al. The incidence of brain metastases in stage IV ROS1-rearranged non-small cell lung cancer and rate of central nervous system progression on crizotinib. J Thorac Oncol 2018;13:1717-26.

99. Lim SM, Kim HR, Lee JS, et al. Open-label, multicenter, 
phase II study of ceritinib in patients with non-small cell lung cancer harboring ROS1 rearrangement. J Clin Oncol 2017;35:2613-8.

100.Siena S, Doebele RC, Shaw AT, et al. Efficacy of entrectinib in patients (pts) with solid tumors and central nervous system (CNS) metastases: integrated analysis from three clinical trials. J Clin Oncol 2019;37:3017.

101.Paz-Ares L, Doebele RC, Farago AF, et al 1130 Entrectinib in NTRK fusion-positive non-small cell lung cancer (NSCLC): integrated analysis of patients enrolled in STARTRK-2, STARTRK-1 and ALKA-372-001. Ann Oncol 2019;30:ii38-68.

102.Huber KV, Salah E, Radic B, et al. Stereospecific targeting of MTH1 by (S)-crizotinib as an anticancer strategy. Nature 2014;508:222-7.

103. Davare MA, Vellore NA, Wagner JP, et al. Structural insight into selectivity and resistance profiles of ROS1 tyrosine kinase inhibitors. Proc Natl Acad Sci USA 2015;112:E5381-90.

104. Ou SH, Tan J, Yen Y, et al. ROS1 as a 'druggable' receptor tyrosine kinase: lessons learned from inhibiting the ALK pathway. Expert Rev Anticancer Ther 2012;12:447-56.

105. Doebele RC, Perez L, Trinh H, et al. Time-to-treatment discontinuation (TTD) and real-world progression-free survival (rwPFS) as endpoints for comparative efficacy analysis between entrectinib trial and crizotinib real-world ROS1 fusion-positive (ROS1+) NSCLC patients. J Clin Oncol 2019;37:9070.

106. Drilon A, Ou SH, Cho BC, et al. A phase 1 study of the next-generation ALK/ROS1/TRK inhibitor ropotrectinib (TPX-0005) in patients with advanced ALK/ROS1/ NTRK-positive cancers (TRIDENT-1). J Clin Oncol 2018;36:2513.

107.Farago AF, Le LP, Zheng Z, et al. Durable clinical response to entrectinib in NTRK1-rearranged non-small cell lung cancer. J Thorac Oncol 2015;10:1670-4.

108. Hyman DM, Laetsch TW, Kummar S, et al. The efficacy of larotrectinib (LOXO-101), a selective tropomyosin receptor kinase (TRK) inhibitor, in adult and pediatric TRK fusion cancers. J Clin Oncol 2017;35:LBA2501.

109. Baik CS, Myall NJ, Wakelee HA. Targeting BRAF-mutant non-small cell lung cancer: from molecular profiling to rationally designed therapy. Oncologist 2017;22:786-96.

110.Zheng G, Tseng LH, Chen G, et al. Clinical detection and categorization of uncommon and concomitant mutations involving BRAF. BMC Cancer 2015;15:779.

111. Yao Z, Torres NM, Tao A, et al. BRAF mutants evade ERK-dependent feedback by different mechanisms that determine their sensitivity to pharmacologic inhibition. Cancer Cell 2015;28:370-83.

112. Yao Z, Yaeger R, Rodrik-Outmezguine VS, et al. Tumours with class 3 BRAF mutants are sensitive to the inhibition of activated RAS. Nature 2017;548:234-8.

113. Noeparast A, Teugels E, Giron P, et al. Non-V600 BRAF mutations recurrently found in lung cancer predict sensitivity to the combination of trametinib and dabrafenib. Oncotarget 2016;8:60094-108.

114. Gautschi O, Peters S, Zoete V, et al. Lung adenocarcinoma with BRAF G469L mutation refractory to vemurafenib. Lung Cancer 2013;82:365-7.

115. Gautschi O, Milia J, Cabarrou B, et al. Targeted therapy for patients with BRAF-mutant lung cancer: results from the European EURAF cohort. J Thorac Oncol 2015;10:1451-7.

116.Dagogo-Jack I, Martinez P, Yeap BY, et al. Impact of BRAF mutation class on disease characteristics and clinical outcomes in BRAF-mutant lung cancer. Clin Cancer Res 2019;25:158-65.

117.Planchard D, Besse B, Kim TM, et al. Updated survival of patients (pts) with previously treated BRAF V600Emutant advanced non-small cell lung cancer (NSCLC) who received dabrafenib (D) or D + trametinib (T) in the phase II BRF113928 study. J Clin Oncol 2017;35:9075.

118. Planchard D, Smit EF, Groen HJM, et al. Dabrafenib plus trametinib in patients with previously untreated BRAF(V600E)-mutant metastatic non-small cell lung cancer: an open-label, phase 2 trial. Lancet Oncol 2017;18:1307-16.

119. Yamamoto G, Sakakibara-Konishi J, Ikari T, et al. Response of BRAFV600E-mutant lung adenocarcinoma with brain metastasis and leptomeningeal dissemination to dabrafenib plus trametinib treatment. J Thorac Oncol 2019;14:e97-9.

120. Loganadane G, Hendriks L, Le Péchoux C, et al. The current role of whole brain radiation therapy in non-small cell lung cancer patients. J Thorac Oncol 2017;12:1467-77.

121. Gerber NK, Yamada Y, Rimner A, et al. Erlotinib versus radiation therapy for brain metastases in patients with EGFR-mutant lung adenocarcinoma. Int J Radiat Oncol Biol Phys 2014;89:322-9.

122. Magnuson WJ, Lester-Coll NH, Wu AJ, et al. Management of brain metastases in tyrosine kinase inhibitor-naive epidermal growth factor receptormutant non-small cell lung cancer: a retrospective multiinstitutional analysis. J Clin Oncol 2017;35:1070.

123.Soon YY, Leong CN, Koh WY, et al. EGFR tyrosine 
kinase inhibitors versus cranial radiation therapy for EGFR mutant non-small cell lung cancer with brain metastases: a systematic review and meta-analysis. Radiother Oncol 2015;114:167-72.

124.Li C, Guo J, Zhao L, et al. Upfront whole brain radiotherapy for multiple brain metastases in patients with EGFR-mutant lung adenocarcinoma. Cancer Manag Res 2019;11:3433-43.

125.Liu S, Qiu B, Chen L, et al. Radiotherapy for asymptomatic brain metastasis in epidermal growth factor receptor mutant non-small cell lung cancer without prior tyrosine kinase inhibitors treatment: a retrospective clinical study. Radiat Oncol 2015;10:118.

126. Chinnaiyan P, Huang S, Vallabhaneni G, et al. Mechanisms of enhanced radiation response following epidermal growth factor receptor signaling inhibition by erlotinib. Cancer Res 2005;65:3328-35.

127. Baumann M, Krause M, Dikomey E, et al. EGFR-targeted anti-cancer drugs in radiotherapy: preclinical evaluation of mechanisms. Radiother Oncol 2007;83:238-48.

128.Zhuang H, Wang J, Zhao L, et al. The theoretical foundation and research progress for WBRT combined with erlotinib for the treatment of multiple brain metastases in patients with lung adenocarcinoma. Int J Cancer 2013;133:2277-83.

129.Zeng YD, Liao H, Qin T, et al. Bloodbrain barrier permeability of gefitinib in patients with brain metastases from non-small cell lung cancer before and during whole brain radiation therapy. Oncotarget 2015;6:8366-76.

130. Welsh JW, Komaki R, Amini A, et al. Phase II trial of erlotinib plus concurrent whole-brain radiation therapy for patients with brain metastases from non-small-cell lung cancer. J Clin Oncol 2013;31:895-902.

131. Zeng YD, Zhang L, Liao H, et al. Gefitinib alone or with concomitant whole brain radiotherapy for patients with brain metastasis from non-smallcell lung cancer: a retrospective study. Asian Pac J Cancer Prev 2012;13:909-14.

132.Li X, Wang Y, Wang J, et al. Enhanced efficacy of AZD3759 and radiation on brain metastasis from EGFR mutant non-small cell lung cancer. Int J Cancer 2018;143:212-24.

133. Wang W, Song Z, Zhang Y. Efficacy of brain radiotherapy plus EGFR-TKI for EGFR-mutated non-small cell lung cancer patients who develop brain metastasis. Arch Med Sci 2018;14:1298-307.

134. Chen CH, Lee HH, Chuang HY, et al. Combination of whole-brain radiotherapy with epidermal growth factor receptor tyrosine kinase inhibitors improves overall survival in EGFR-mutated non-small cell lung cancer patients with brain metastases. Cancers (Basel) 2019. doi: 10.3390/cancers11081092.

135.Ke SB, Qiu H, Chen JM, et al. Therapeutic effect of firstline epidermal growth factor receptor tyrosine kinase inhibitor (EGFR-TKI) combined with whole brain radiotherapy on patients with EGFR mutation-positive lung adenocarcinoma and brain metastases. Curr Med Sci 2018;38:1062-8.

136. He ZY, Li MF, Lin JH, et al. Comparing the efficacy of concurrent EGFR-TKI and whole-brain radiotherapy vs EGFR-TKI alone as a first-line therapy for advanced EGFR-mutated non-small cell lung cancer with brain metastases: a retrospective cohort study. Cancer Manag Res 2019;11:2129-38.

137.Jiang T, Su C, Li X, et al. EGFR TKIs plus WBRT demonstrated no survival benefit other than that of TKIs alone in patients with NSCLC and EGFR mutation and brain metastases. J Thorac Oncol 2016;11:1718-28.

138. Doherty MK, Korpanty GJ, Tomasini P, et al. Treatment options for patients with brain metastases from EGFR/ALKdriven lung cancer. Radiother Oncol 2017;123:195-202.

139. Borghetti $\mathrm{P}$, Bonù ML, Giubbolini R, et al. Concomitant radiotherapy and TKI in metastatic EGFR or ALKmutated non-small cell lung cancer: a multicentric analysis on behalf of AIRO lung cancer study group. Radiol Med 2019;124:662-70.

140. Sharma SV, Bell DW, Settleman J, et al. Epidermal growth factor receptor mutations in lung cancer. Nat Rev Cancer 2007;7:169-81.

141. Kobayashi Y, Mitsudomi T. Not all epidermal growth factor receptor mutations in lung cancer are created equal: perspectives for individualized treatment strategy. Cancer Sci 2016;107:1179-86.

142. Riely GJ, Pao W, Pham D, et al. Clinical course of patients with non-small cell lung cancer and epidermal growth factor receptor exon 19 and exon 21 mutations treated with gefitinib or erlotinib. Clin Cancer Res 2006;12:839-44.

143.Jackman DM, Yeap BY, Sequist LV, et al. Exon 19 deletion mutations of epidermal growth factor receptor are associated with prolonged survival in non-small cell lung cancer patients treated with gefitinib or erlotinib. Clin Cancer Res 2006;12:3908-14.

144. Yang JJ, Zhou Q, Yan HH, et al. A phase III randomised controlled trial of erlotinib vs gefitinib in advanced nonsmall cell lung cancer with EGFR mutations. Br J Cancer 2017;116:568-74. 
145. Urata Y, Katakami N, Morita S, et al. Randomized phase III study comparing gefitinib with erlotinib in patients with previously treated advanced lung adenocarcinoma: WJOG 5108L. J Clin Oncol 2016;34:3248-57.

146.Paz-Ares L, Tan EH, O'Byrne K, et al. Afatinib versus gefitinib in patients with EGFR mutation-positive advanced non-small cell lung cancer: overall survival data from the phase IIb LUX-Lung 7 trial. Ann Oncol 2017;28:270-7.

147.Wu YL, Cheng Y, Zhou X, et al. Dacomitinib versus gefitinib as first-line treatment for patients with EGFRmutation-positive non-small cell lung cancer (ARCHER 1050): a randomised, open-label, phase 3 trial. Lancet Oncol 2017;18:1454-66.

148. Mok TS, Cheng Y, Zhou X, et al. Improvement in overall survival in a randomized study that compared dacomitinib with gefitinib in patients with advanced non-small cell lung cancer and EGFR-activating mutations. J Clin Oncol 2018;36:2244-50.

149. Soria JC, Ohe Y, Vansteenkiste J, et al. Osimertinib in untreated EGFR-mutated advanced non-small cell lung cancer. N Engl J Med 2018;378:113-25.

150. Available online: https://www.esmo.org/Press-Office/PressReleases/ESMO-Congress-NSCLC-cancer-osimertinibFlaura-Ramalingam (accessed October 19, 2019).

151.Dong K, Liang W, Zhao S, et al. EGFR-TKI plus brain radiotherapy versus EGFR-TKI alone in the management of EGFR-mutated NSCLC patients with brain metastases. Transl Lung Cancer Res 2019;8:268-79.

152. Li H, Cao J, Zhang X, et al. Correlation between status of epidermal growth factor receptor mutation and distant metastases of lung adenocarcinoma upon initial diagnosis based on 1063 patients in China. Clin Exp Metastasis 2017;34:63-71.

153.Li B, Sun SZ, Yang M, et al. The correlation between EGFR mutation status and the risk of brain metastasis in patients with lung adenocarcinoma. J Neurooncol 2015;124:79-85.

154. Takano K, Kinoshita M, Takagaki M, et al. Different spatial distributions of brain metastases from lung cancer by histological subtype and mutation status of epidermal growth factor receptor. Neuro Oncol 2016;18:716-24.

155. Okuda Y, Sato K, Sudo K, et al. Low plasma concentration of gefitinib in patients with EGFR exon 21 L858R point mutations shortens progression-free survival. Cancer Chemother Pharmacol 2017;79:1013-20.

156. Li H, Zhang X, Cao J, et al. Exon 19 deletion of epidermal growth factor receptor is associated with prolonged survival in brain metastases from non-small cell lung cancer. Tumour Biol 2015;36:7333-4.

157. Tsao MN, Lloyd N, Wong RK, et al. Whole brain radiotherapy for the treatment of newly diagnosed multiple brain metastases. Cochrane Database Syst Rev 2012;18:CD003869.

158. Gaspar LE, Mehta MP, Patchell RA, et al. The role of whole brain radiation therapy in the management of newly diagnosed brain metastases: a systematic review and evidence-based clinical practice guideline. J Neurooncol 2010;96:17-32.

159.Xue J, Kubicek GJ, Grimm J, et al. Biological implications of whole-brain radiotherapy versus stereotactic radiosurgery of multiple brain metastases. J Neurosurg 2014;121 Suppl:60-8.

160. Kaul D, Angelidis A, Budach V, et al. Prognostic indices in stereotactic radiotherapy of brain metastases of non-small cell lung cancer. Radiat Oncol 2015;10:244.

161.Hartgerink D, van der Heijden B, De Ruysscher D, et al. Stereotactic radiosurgery in the management of patients with brain metastases of non-small cell lung cancer: indications, decision tools and future directions. Front Oncol 2018;8:154.

162. Brown PD, Jaeckle K, Ballman KV, et al. Effect of radiosurgery alone vs radiosurgery with whole brain radiation therapy on cognitive function in patients with 1 to 3 brain metastases: a randomized clinical trial. JAMA 2016;316:401-9.

163. Cai L, Qiu X, Yang H, et al. Evaluation on efficacy and safety of the addition of $\mathrm{X}$-knife therapy to gefitinib in NSCLC patients with symptomatic brain metastases. Oncotarget 2016;8:57470-6.

164. Yamamoto M, Serizawa T, Shuto T, et al. Stereotactic radiosurgery for patients with multiple brain metastases (JLGK0901): a multi-institutional prospective observational study. Lancet Oncol 2014;15:387-95.

165. Lee JH, Chen HY, Hsu FM, et al. Cranial irradiation for patients with epidermal growth factor receptor (EGFR) mutant lung cancer who have brain metastases in the era of a new generation of EGFR inhibitors. Oncologist 2019. doi: 10.1634/theoncologist.2019-0152.

166. Monaco EA 3rd, Faraji AH, Berkowitz O, et al. Leukoencephalopathy after whole-brain radiation therapy plus radiosurgery versus radiosurgery alone for metastatic lung cancer. Cancer 2013;119:226-32.

167.Mulvenna P, Nankivell M, Barton R, et al. Dexamethasone and supportive care with or without whole brain radiotherapy in treating patients with non- 
small cell lung cancer with brain metastases unsuitable for resection or stereotactic radiotherapy (QUARTZ): results from a phase 3 , non-inferiority, randomised trial. Lancet 2016;388:2004-14.

168.Xing P, Mu Y, Hao X, et al. Data from real world to evaluate the efficacy of osimertinib in non-small cell lung cancer patients with central nervous system metastasis. Clin Transl Oncol 2019;21:1424-31.

169. Goss G, Tsai CM, Shepherd FA, et al. Osimertinib for pretreated EGFR Thr790Met-positive advanced nonsmall cell lung cancer (AURA2): a multicentre, open-label, single-arm, phase 2 study. Lancet Oncol 2016;17:1643-52.

170. Brastianos PK, Carter SL, Santagata S, et al. Genomic characterization of brain metastases reveals branched evolution and potential therapeutic targets. Cancer Discov 2015;5:1164-77.

171.Hata A, Katakami N, Yoshioka H, et al. Rebiopsy of non-small cell lung cancer patients with acquired resistance to epidermal growth factor receptor-tyrosine kinase inhibitor: comparison between T790M mutationpositive and mutation-negative populations. Cancer 2013;119:4325-32.

172.Hata A, Katakami N, Yoshioka H, et al. Spatiotemporal T790M heterogeneity in individual patients with EGFRmutant non-small cell lung cancer after acquired resistance to EGFR-TKI. J Thorac Oncol 2015;10:1553-9.

173. Yun J, Hong MH, Kim SY, et al. YH25448, an irreversible EGFR-TKI with potent intracranial activity in EGFR mutant non-small cell lung cancer. Clin Cancer Res 2019;25:2575-87.

174. Kris MG, Johnson BE, Berry LD, et al. Using multiplexed assays of oncogenic drivers in lung cancers to select targeted drugs. JAMA 2014;311:1998-2006.

175.Jordan EJ, Kim HR, Arcila ME, et al. Prospective comprehensive molecular characterization of lung adenocarcinomas for efficient patient matching to approved and emerging therapies. Cancer Discov 2017;7:596-609.

176. Dawe DE, Greenspoon JN, Ellis PM. Brain metastases in non-small-cell lung cancer. Clin Lung Cancer 2014;15:249-57.

177. Sperduto PW, Yang TJ, Beal K, et al. Estimating survival in patients with lung cancer and brain metastases: an update of the graded prognostic assessment for lung cancer using molecular markers (Lung-molGPA). JAMA Oncol 2017;3:827-31.

178. Rades D, Hansen HC, Schild SE, et al. A new diagnosisspecific survival score for patients to be irradiated for brain metastases from non-small cell lung cancer. Lung 2019;197:321-6.
Cite this article as: Spagnuolo A, Muto M, Monaco F, Colantuoni G, Gridelli C. The optional approach of oncogeneaddicted non-small cell lung cancer with brain metastases in the new generation targeted therapies era. Transl Lung Cancer Res 2019;8(6):1134-1151. doi: 10.21037/tlcr.2019.12.24 